\title{
Analysis and improvement possibilities of waste management at Kuwait Oil Company (KOC)
}

\author{
Y. Al Qallaf, S. Al-Kandari, K. Yousef, S. Al Mutairi \& H. Fouzy \\ Kuwait Oil Company, Kuwait
}

\begin{abstract}
Kuwait Oil Company (KOC), a subsidiary of Kuwait Petroleum Corporation $(\mathrm{KPC})$, is involved in exploration, drilling and the production of oil and gas. The issue of waste management in KOC represents a more in-depth account of the field and covers conceptual analyses of different types of waste streams (solid, liquid, and sludge), the activity upon waste, and a holistic view of the goals of waste management. The increasing amount of waste generated, which is exacerbated by a lack of proper waste management, is of growing concern worldwide and in the main cities in developing countries due to its social, economic and environmental implications. Waste management practices are founded on the expectation that waste management is to prevent waste causing harm to human health and the environment. KOC always ensures that the generated waste be managed effectively in compliance with applicable regulations of Kuwait Environment Public Authority and KOC HSE management system (HSEMS) procedures implemented for KOC facilities. Also, KOC plays an active role in facing the adverse effects of waste through the implementation of many of the services and development new projects in the areas of collection and recycling, waste treatment and by focusing on the development of long-term waste management strategy for all over the company areas. This study was conducted to analysis and improvement possibilities on waste management at KOC. In addition, in this paper we will discuss various processes used in $\mathrm{KOC}$ areas indicating how waste is being managed.

Keywords: hazardous waste, non-hazardous waste, waste management, HSE management system.
\end{abstract}




\section{Introduction}

Kuwait Oil Company (KOC), established in 1934, is one of the largest oil exporters in the world, with its headquarters in Kuwait. The company's activities have extended to include exploration operations, onshore and offshore surveys, drilling of test wells, and developing of producing fields in addition to crude and natural gas exploration.

All over the world today, waste management and disposal remain critical issues of the day, not only because of challenging views of the best methods of managing waste, and the role of households, neighborhoods, and governments but also and more importantly on the strategies to change people's culture values and attitudes. The activities of environmentalists especially in Europe have increased both the level of awareness about the need for the safe environment and the pressure on governments to do more regarding policy. In financing public enlightenment and education, the pressure on the government is essential because "waste management and disposal involve important institutional as well as technical problems" [1].

Most of the public think that waste is cheap material to be thrown away and that it cannot be reused for useful purposes. This indicates the inattention of citizens to waste as a great resource.

According to the Kuwait Central Statistical Bureau [2], quantities of waste are increasing annually. The percentages of different types of waste in the MSW stream in Kuwait are represented in Figure 1, based on data from the Industrial Bank of Kuwait [4]. As shown in Figure 1, organic waste constitutes the largest proportion of waste, making up 50\%, whereas paper and plastic come in second and third positions with $21 \%$ and $13 \%$, respectively.

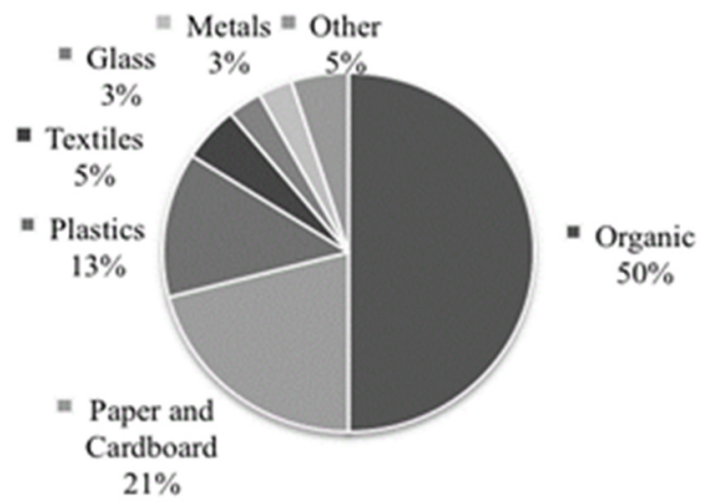

Figure 1: Composition of the MSW stream in Kuwait.

The current waste management system in Kuwait are randomly dumped into landfills without considering safety and environmental precautions from the point of collection and transportation to the last step of final cover in a landfill [2]. 
Waste in KOC is categorized into solids, liquids, and gases. This study discusses the waste management improvement that is classified according to its resource and material types. The general categories of waste material have also been developed. The different categories of waste are defined below:

\subsection{Non-hazardous waste}

Unwanted materials/substances other than the hazardous. They could be in the form of a solid, sludge, slurry and liquid. The exceptions are surplus/expired materials that are returned to the manufacturer or supplier.

\subsection{Hazardous waste}

Any waste (solid, sludge, slurry and liquid) which is either combustible, explosive, inflammable, corrosive, reactive or toxic; the list of known hazardous and nonhazardous waste encountered in KOC operations. KOC is always looking throughout the projects developed for waste management for new technology or service becoming available which allows for more efficient management of a particular waste stream.

$\mathrm{KOC}$ is well aware that waste generation from its operations is a subject of concern as there are serious consequences associated with its mismanagement, such as:

- Environment impact - soil and water contamination;

- Human health impact;

- Recycle/resale/scrap value of waste lost;

- Non-compliance with local government regulation and standards;

- Unaesthetic sight that may affect company image;

- A burden on the company for clean-up/restoration of the area.

\section{Waste management philosophy at KOC}

The goal of this study to highlight the KOC's waste management philosophy that focuses on reducing the waste volumes and to handle any waste that is generated in an economical and environmentally sound manner. This philosophy is supported by the KOC HSE management system in the following statements:

- Policy and strategic objectives

Implement measures to reduce waste and minimize the consumption of materials, fuel, and energy.

- Evaluation and risk management

A comprehensive waste management plan developed and implemented. This includes maintaining an inventory of all waste generated or stored on site. Waste that cannot be recycled or reused is disposed of in a manner that minimizes its safety and environmental impact.

\subsection{KOC waste management procedures}

Waste generated by $\mathrm{KOC}$ activities is managed in compliance with applicable HSEMS procedures: 
- $\quad$ KOC.EV.008 - waste management procedure;

- KOC.EV.004 - management of wastewater discharge procedure.

\subsection{Kuwait Environment Public Authority regulations}

The management of waste is regulated by Law No. 21/1995 as amended by Law No. 16/1996 and Decision 210/2001 and amended by Law No.42 of 2014. This categorizes waste as hazardous or non-hazardous according to the Basel Protocol. For movements of waste within Kuwait, it requires that a manifest for transportation and disposal is completed, and the manifests must be supplemented according to whether the waste is hazardous or non-hazardous.

\section{Waste management projects at KOC}

Waste management projects have been developed at KOC to manage all types and quantities of waste generated within the company's sites. Currently KOC waste (hazardous/non-hazardous) is collected from more than various 300 distant locations, which consists of offices, operational facilities, camps, workshops, fire and booster stations drilling sites, security posts, water treatment/injection plant "South \& East Kuwait (S\&EK), West Kuwait (WK), North Kuwait (NK), Export \& Marine Operation (E\&MO), Gas operation and Ahmadi Town Hall" (shown in Figure 2).

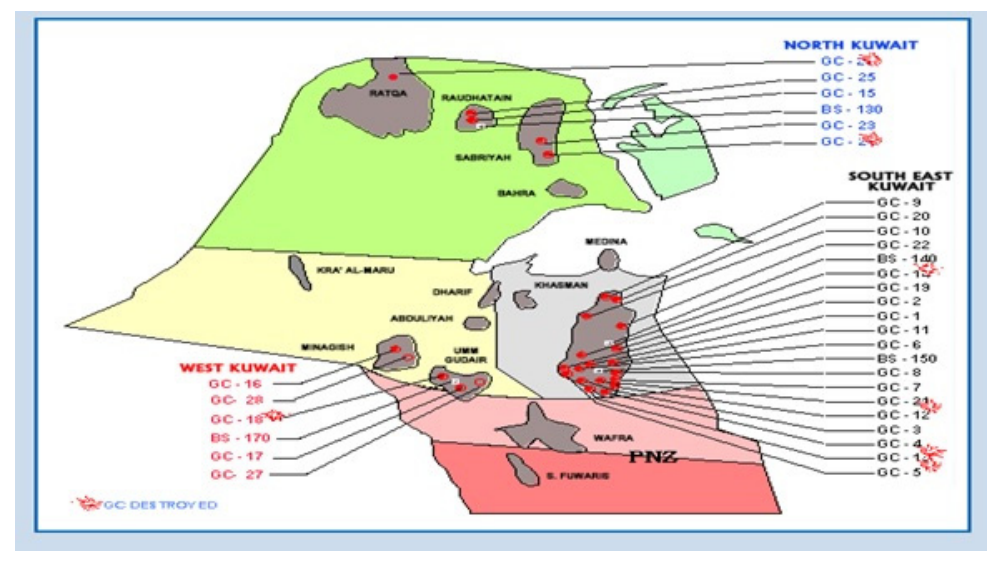

Figure 2: Waste generated from all KOC facilities.

All types of waste are collected, stored, transported, treated and disposed of in a safe and protected area in compliance with all regulations (as shown in Figure 2).

\subsection{Collection}

Hazardous and non-hazardous waste from all KOC facilities, installations, and operations. 


\subsection{Segregation}

Separate and recover recyclable waste to minimize environmental impact of KOC operations.

\subsection{Treatment}

Recover crude oil, reduce environmental hazards.

\subsection{Disposal}

Transport waste to KEPA approved disposal facilities.

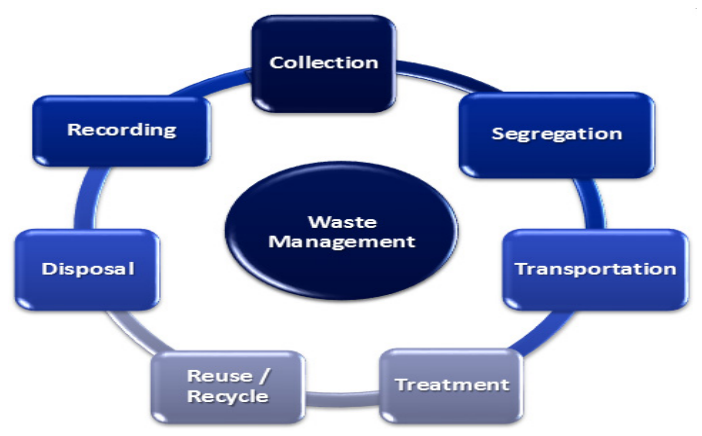

Figure 3: Waste management process at KOC.

The waste materials at KOC are subjected to reduction, re-use or recycling, recovery or disposal and to dispose them properly to Kuwait Environment Public Authority (KEPA)/Company approved locations.

After collection and segregation, the waste from all $\mathrm{KOC}$ areas is transported to the transfer stations. Transfer stations are the intermediate points between the collection of waste and transportation to recycling and disposal facilities [5]. KOC's waste is transported in vehicles fitted with a vehicle tracking system for monitoring the proper transfer to designated locations. The time required for the collection and transportation of solid waste should not exceed either the period for the waste to rot and start releasing odors or the period for fly breeding (to avoid disease transmission) [6].

KOC's strategy is to manage and document all types and quantities of waste produced or generated at the KOC areas and to route correctly and dispose of them at approved locations.

\subsubsection{Waste management projects}

1. Waste management within the company's operational area.

2. Environmental waste management at Ahmadi Township.

3. Turning waste to values in D\&T Directorate by detoxifying OBM drill cutting waste using thermo-mechanical cutting cleaning technology. 


\section{Waste determination process}

Before discarding a material, a waste determination process must be undertaken to decide how to dispose of it appropriately and legally. $\mathrm{KOC}$ is conducting an adequate determination for each waste stream and properly documenting which this decision will help all facilities stay in compliance and avoid costly errors. Appropriate determinations are the foundation of any hazardous and nonhazardous waste management program and will contribute to reducing administration and disposal costs. Everything we use goes through a life cycle (Food we eat and the goods (stuff) we use), and each stage of the life cycle has environmental impacts, including climate change. However, reducing the use of materials in every stage of the life cycle minimizes the environmental impact associated with the stuff we use (shown in Figure 4).

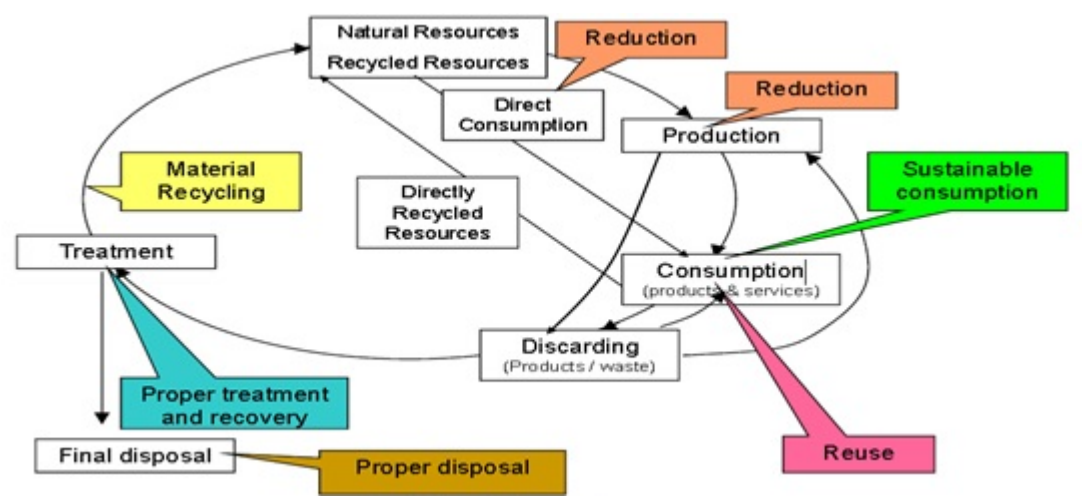

Figure 4: Waste determination process.

The waste handling option at KOC is based on the following hierarchy of preference:

\subsection{Source reduction}

Any action or process that causes a reduction in the generation of waste. The best and most cost effective method of dealing with waste is not to generate it in the first place. If waste must be produced, the amounts generated should be minimized.

\subsection{Reuse/recycle}

The process of finding alternative and beneficial uses for a material that would otherwise be considered waste. Examples include the reclamation of lubricating oils and the collection and recycling of aluminum cans and paper.

\subsection{Treatment}

Many hazardous waste streams can be treated to render the material less hazardous or non-hazardous. Examples of treatment include solidification, neutralization, and incineration. 


\subsection{Disposal}

This is the last of the handling options. When this point is reached, it should mean that all reasonable efforts to use one of the other three methods have been exhausted. In many cases, disposal is the only real economically viable option. However, every effort should be made to reduce the amount of waste sent to disposal.

\section{Waste information collection}

The quantities of all waste generated and disposed of must be recorded to ensure that all waste arising from all KOC activities are managed and disposed of legally. This requires that there is a system to record all waste that arise and track their movements until final disposal. Two types of record keeping has been implemented in $\mathrm{KOC}$ :

1. KOC has developed waste data forms for non-hazardous waste (types of nonhazardous waste are shown in Table 1) and hazardous waste (types of hazardous waste are shown in Table 2) for record reference these records of waste generated for all KOC areas.

Table 1: Non-hazardous waste streams and sources.

\begin{tabular}{|c|l|}
\hline General Waste & - Mix garbage \\
\hline Paper & • Cardboard, office waste papers, magazines etc, \\
\hline Plastic & $\begin{array}{l}\text { - HDPE \&LDPE bottles, containers, pipes, cables, packaging material } \\
\text { etc. }\end{array}$ \\
\hline Glass & • Soft drinks, lab reagents bottles \\
\hline Metal & $\begin{array}{l}\text { - Aluminum soft drink tins, steel pipes, metal scrap, drums, redundant } \\
\text { flow lines etc. }\end{array}$ \\
\hline Wood & - Wooden Pallets \\
\hline Concrete & - Construction \& demolition Waste \\
\hline Tires & - Vehicle tires \\
\hline Food Waste & • Food waste from offices and cafeterias \\
\hline
\end{tabular}

Table 2: Hazardous waste streams and sources.

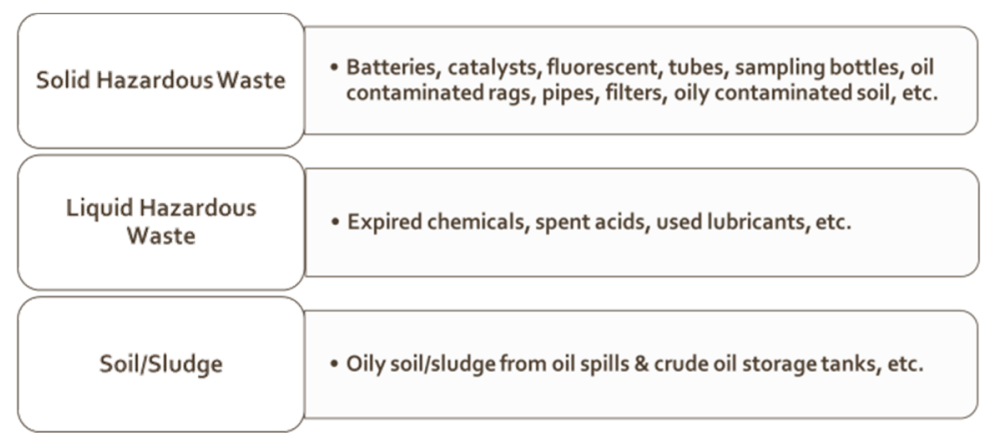


2. All waste transfer to approved recycle, and disposal locations outside KOC fence are registered through a manifest form for hazardous and non-hazardous waste.

\section{Analysis of KOC's management system}

The collected waste from the KOC areas are segregated into recyclable and nonrecyclables (Hazardous \& Non- Hazardous) waste where the segregation area is to minimize environmental impact in KOC operations.

Processing of the recyclable waste is carrying out by segregating all the recyclable materials, which all are bailed and sent to recycling companies also the food waste is mixed with organic waste using the compost machine and the composite organic waste is being used as fertilizer. Treatment of hazardous waste at KOC to convert it into non-hazardous substances or to stabilize or encapsulate the waste so that it will not migrate and present a hazard when released in environment

The treatment techniques implemented in waste management projects at $\mathrm{KOC}$ as the following:

- Solidification of expired chemicals;

- Soil washing for the contaminated soil;

- Bioremediation for contaminated soil.

Treatment of the oil-based mud cuttings are done using a unique thermomechanical cuttings cleaner (TCC) technology. The TCC technology is a most environment friendly soil remediation method with proven effectiveness around the globe. This technology provides indirect and controlled heating by converting friction energy to kinetic energy to remove hydrocarbons undestroyed. Thermal desorption uses a non-oxidizing process to vaporize volatiles and semivolatiles through the application of heat because thermal desorption depends on volatilization, treatment efficiency is related to the volatility of the contaminant. Thermal desorption easily removes light hydrocarbons, aromatics, and other volatile organics, but heavier compounds such as polycyclic aromatic hydrocarbons are less easily removed. Low-temperature thermal desorption systems typically operate at 250 to $350^{\circ} \mathrm{C}$ and may be sufficient to treat waste with light hydrocarbons, aromatics (e.g., benzene, toluene, ethyl benzene, and xylenes), and other volatile organics, which are easily removed. Recovered hydrocarbons are reusable as base fluid for making fresh OBM, the recovered water is reused to moisturize treated drilling cuttings, and hydrate treated soils. Indirect heating is safer and minimizes the pollution compared to direct heating.

\section{Results and discussion}

Thus, this study was conducted to describe the analysis and improvement possibilities of waste management at KOC including the evaluation waste management process and the proper management of $\mathrm{KOC}$ waste. 
Our research study focuses on all types of waste by using the data based on the KOC waste monitoring system according to waste classification for the years of 2014 and 2015.

Cumulative data from all KOC operational areas (WK, Gas, CSD, D\&T, NK, S\&E, EO\&MO Ahmadi Area). All waste values are expressed in metric ton for solids and cubic meters for liquid waste streams.

In 2014, KOC generated around 20120.21 M Ton $/ \mathrm{m}^{3}$ of waste in the type of hazardous and non-hazardous, were arises from all KOC areas, where was the amount of non-hazardous waste was $14752.3 \mathrm{M} \mathrm{Ton} / \mathrm{m}^{3}$ (shown in Figure 5) and the quantity of hazardous waste $5209.54 \mathrm{M} \mathrm{Ton} / \mathrm{m}^{3}$ (shown in Figure 6).

Total Non-Hazardous Waste Quantity Collected- 14752.3 MT

(Jan - 2014-Dec. 2014)

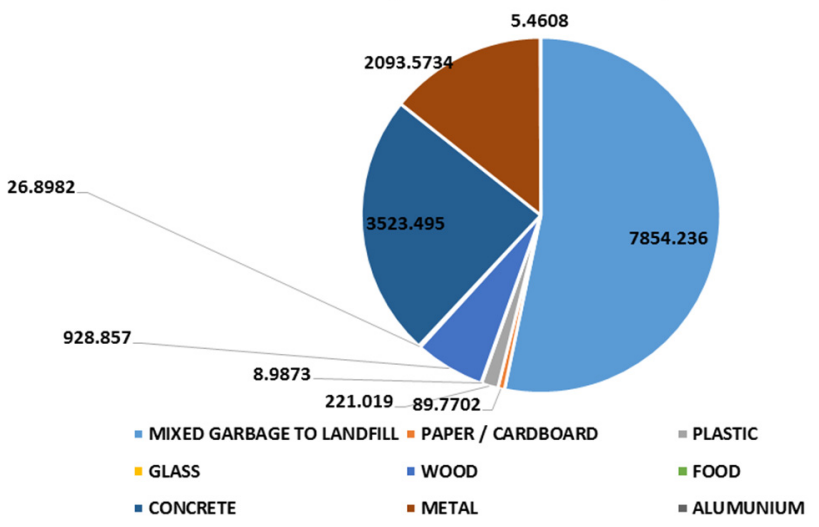

Figure 5: Amount of non-hazardous waste - 2014 .

In 2014, roughly one-third of the hazardous waste was oily water, another third asbestos and another third contaminated soil. Other marginal sources of hazardous waste include domestic and sewage sludge, cleaning waste, drilling cutting, and a small portion of general waste.

Oil contaminated soil and oily sludge generated as a result of company activities are treated within KOC operational areas. Bioremediation and soil washing treatment processes are used for the treatment.

The recovered oil from the treatment is recycled back to crude oil recovery plants, and the treated soil is re-used within the company's operational areas for various backfilling purposes such as backfilling abandoned Gatch pits, trenches, etc.

Sewage management: sewage, which is generated from all KOC facilities. Currently, three (3) STPs with $300 \mathrm{~m}^{3} /$ day design capacity each is installed and being operated, which treat all the sewage generated within the company's operational areas after that the treated water is reused for various irrigation purposes. 


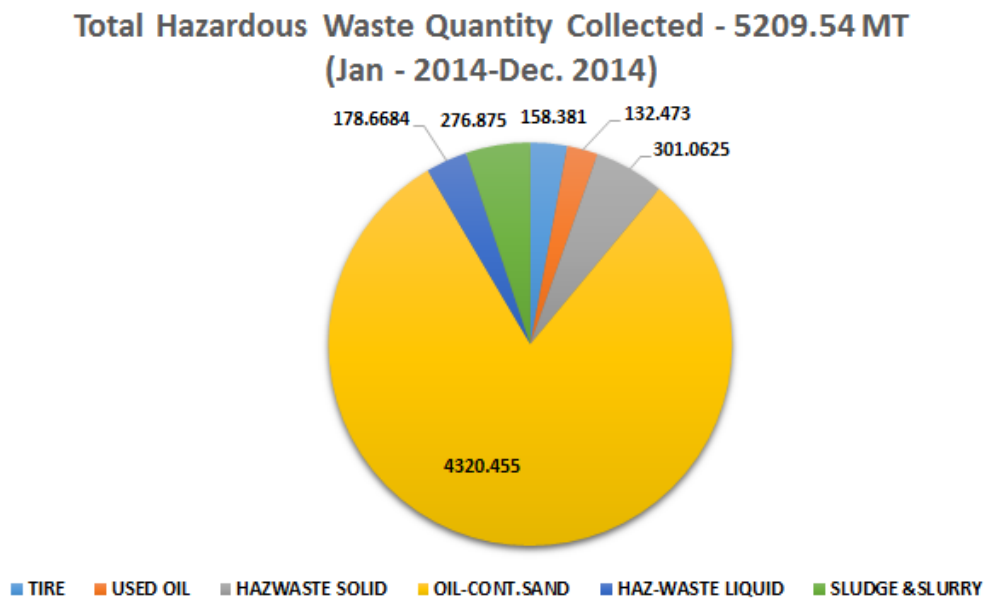

Figure 6: Amount of hazardous waste -2014 .

In $2015 \mathrm{KOC}$ generated around $30400.4 \mathrm{M}$ Ton $/ \mathrm{m}^{3}$ of waste in the type of hazardous and non-hazardous, arising from all KOC areas, where the amount of non-hazardous waste was $13894.76 \mathrm{M}$ Ton $/ \mathrm{m}^{3}$ (shown in Figure 7), and the quantity of hazardous waste $16437.2 \mathrm{M}$ Ton $/ \mathrm{m}^{3}$ (shown in Figure 8).

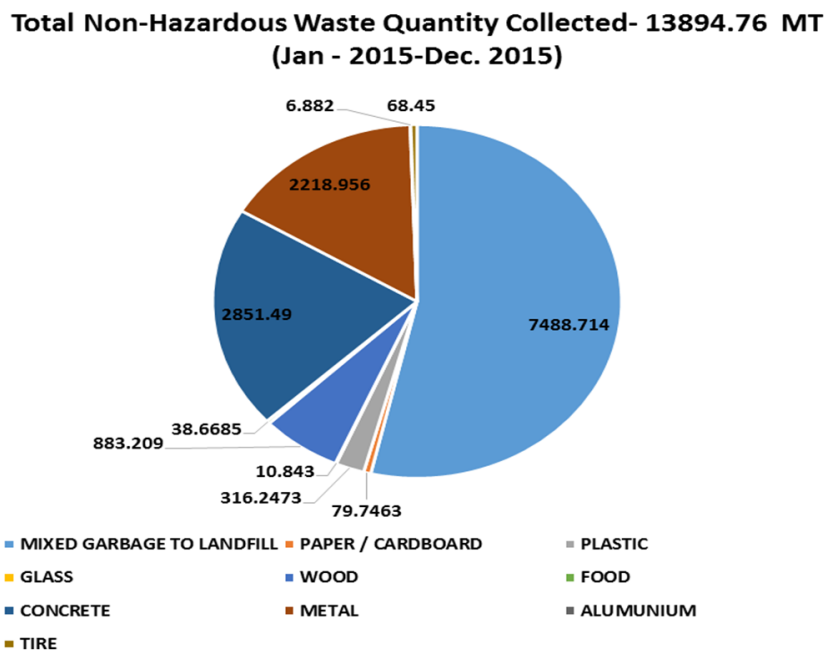

Figure 7: Amount of non-hazardous waste - 2015 .

In $2014 / 15$, roughly, $57 \%$ of the hazardous waste was soil contaminated, another half $32 \%$ domestic and sewage sludge. Other marginal sources of hazardous waste include asbestos, cleaning waste, drilling cutting, and a small portion of general waste. 
Total Hazardous Waste Quantity Collected -

16437.2 MT (Jan - 2015 - Dec. 2015)

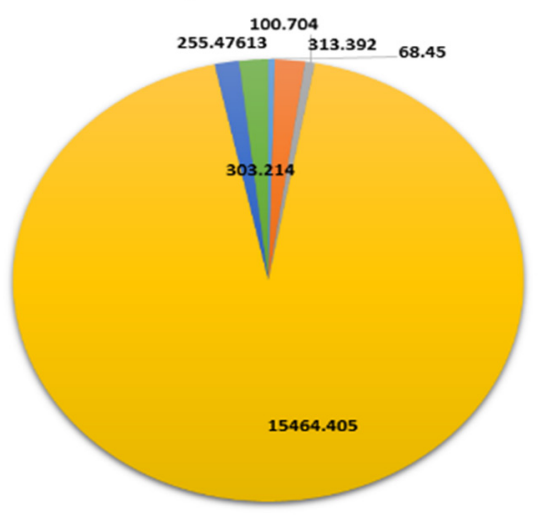

$=$ TIRE $=$ USED OIL = HAZWASTE SOLID $=$ OIL-CONT.SAND $=$ HAZ-WASTE LIQUID $\equiv$ SLUDGE \&SLURRY

Figure 8: Amount of hazardous waste - 2015.

\section{Conclusion}

The effect that waste has on our natural environment and ultimately on the quality of our life has been made public in worldwide discussions. The problems related to waste have many scopes. In economically challenged communities, the scope and magnitude of the problem may often exceed the capacity that local authorities have to effectively resolve issues of waste collection and disposal, in addition to other difficult city managerial tasks.

The results obtained from the analysis of the waste management in KOC show a growing and dynamic entity with issues of development, and environmental hazards in particular in water and soil contamination

KOC has achieved some positive results in the form of recycling surplus material through salvage vendors and encouraging recycling of office paper waste and the contaminated soil is treated and recover crude oil to reduce environmental hazards and further use the treated soil for backfilling.

This study examines the waste management system in KOC. This study revealed that $57 \%$ of the hazardous waste was soil contaminated, another half $32 \%$ domestic and sewage sludge. Other marginal sources of hazardous waste include asbestos, cleaning waste, drilling cutting, and a small portion of unspecified waste.

KOC reached initiatives in waste management and also has been making every effort to maximize the opportunities of waste reduction, reuse, recycling of waste and material recovery, such as:

- To prevent waste generation, where possible;

- To encourage minimizing waste generation by implementing waste minimization techniques, such as:

- improved operating practices;

- $\quad$ proper chemical and material storage; 
- purchasing and inventory control;

- spill and leak prevention.

- To promote awareness among the company employees on a number of waste management issues and encourage moving towards zero waste approach.

- To ensure proper segregation of recyclables (i.e., paper, plastic, glass, metal, food waste etc.) within hazardous/non-hazardous waste and send it for recycling.

- To compost food waste, which is used as soil conditioner and fertilizer in landscaping and horticulture purposes.

- To send scrap metal to KOC metal scrap yard, where scrap is sold to metal recycling company.

- To reuse empty metal drums where possible, or else sent to KOC metal scrap yard

- To recover oil to maximum extend from oily waste (oil contaminated, oily sludge soils) and send it back to oil recovering system within KOC.

- To provide necessary awareness on waste management to schoolchildren and community.

- To participate in waste management conferences to share knowledge with experts to improve and develop waste management and developing strategy for KOC.

\section{References}

[1] Report of the Nuclear Energy Policy Study Group, Nuclear Power Issues and Choices, Cambridge, Ballinger Pub. Co., 1977.

[2] Kuwait Central Statistical Bureau, Annual statistical Abstract, Kuwait: Central Statistical Bureau, 2011.

[3] ISO 14001: 2004 - Environmental Management System - Requirements with guidance for use.

[4] The Industrial Bank of Kuwait, (eds). Assessment of Solid Waste Sector in the State of Kuwait, Kuwait, pp. 8-17, 2010.

[5] Environmental Biotechnology Group, Transfer and Transport; Turkey, Online. http://mebig.marmara.edu.tr/Enve330/Chapter10.pdf

[6] Davis M, Cornwell D, Introduction to Environmental Engineering, fourth edition, McGraw Hill Higher Education, pp. 745-747, 2007. 